\title{
A PERSONAGEM E A MEMÓRIA EM DOIS ROMANCES DE LÍDIA JORGE
}

\author{
Paula Renata Lucas Collares Ramis ${ }^{1}$
}

\begin{abstract}
RESUMO: Em $A$ costa dos murmúrios (1988), a personagem Eva Lopo através do seu discurso, situado vinte anos após os acontecimentos, expõe os conflitos da guerra pela independência em Moçambique (África) e, principalmente, mostra-nos como a mulher era tratada em tal contexto. Em A noite das mulheres cantoras (2011), encontramos a personagem Solange de Matos que, afastada vinte e um anos dos eventos, também olha para o passado na tentativa de reviver e entender os momentos vividos no território do «império minuto». A partir dessas duas narrativas, da escritora Lídia Jorge, pretende-se analisar como as duas mulheres (Eva Lopo e Solange Matos) regressam ao passado e reorganizam o presente. Intenciona-se investigar como tais personagens adotam perspectivas diferentes em relação aos acontecimentos históricos, especialmente mostrando como elas reconstituem a experiência do passado, considerando que a memória não permite o reviver, mas é reelaborada a partir da narrativização.
\end{abstract}

PALAVRAS-CHAVE: Lídia Jorge; Memória; Mulher; Metaficção.

\section{THE CHARACTER AND THE MEMORY IN TWO ROMANCES OF LÍDIA JORGE}

\begin{abstract}
In A costa dos murmúrios (1988), the character Eva Lopo through her speech, situated twenty years after the events, exposes the conflicts of the war for independence in Mozambique (Africa) and, mainly, shows us how the woman was treated in such a context. In $A$ noite das mulheres cantoras (2011), we find the character Solange de Matos, who, twenty-one years away from the events, also looks back at the past in an attempt to revive and understand the moments lived in the territory of the "minute empire." From these two narratives, written by the writer Lídia Jorge, we intend to analyze how the two women (Eva Lopo and Solange Matos) return to the past and reorganize the present. It is intended to investigate how such characters adopt different perspectives in relation to historical events, especially showing how they reconstitute the experience of the past, considering that memory does not allow the revival, but is re-elaborated from the narrativization.
\end{abstract}

KEY WORDS: Lídia Jorge; Memory; Woman; Metafiction.

Santo Agostinho, no Livro X, fala-nos da grande potência da memória, capaz de guardar uma "multiplicidade profunda e infinita" de informações (1987, p.234). Contudo, também devemos considerar que o esquecimento é próprio da memória: “a memória retém o esquecimento" (AGOSTINHO, 1987, p.233). A memória jamais conseguirá reconstituir com exatidão o passado. $\mathrm{O}$ passado não ressurge apenas como lembrança de um tempo vivido, mas é reatualizado no momento da enunciação. A memória é uma temática muito recorrente na obra de Lídia Jorge, como poderemos observar a partir dos romances $A$ costa dos murmúrios e $A$ noite das mulheres cantoras. A escrita da autora compactua com a nova literatura portuguesa, pós 25 de Abril, ao considerar que a memória é um espaço para

\footnotetext{
${ }^{1}$ Doutora em Letras (PUCRS). Bolsista de Pós-Doutorado (CAPES/UFPel).
} 
construção identitária e que o passado é um paradigma constantemente revisitado e questionado.

Eva e Solange, personagens dos dois romances, tornam-se ficcionistas, são leitoras das suas histórias. O romance $A$ costa dos murmúrios, publicado em 1988, apresenta uma estrutura bipartida. Primeiramente, temos uma espécie de conto intitulado Os gafanhotos, narrado por um narrador heterodiegético e que apresenta início, meio e fim. Em Os gafanhotos é narrado o matrimônio do alferes Luís Alex com Evita, estudante de História. O evento acontece no hotel Stella Maris, em Beira, Moçambique.

Os gafanhotos é narrado vinte anos após os acontecimentos e o narrador pretende ser fiel aos fatos narrando-os da forma mais mimética possível. Apesar da distância temporal, o narrador parece recordar com precisão e clareza os eventos. Entretanto, os pequenos espaços que serão preenchidos no segundo relato já evidenciam ali uma desconstrução da História oficial, assim como salientam que a memória é um processo ativo que permite fazer escolhas. É na leitura do segundo relato que percebemos as lacunas d'Os gafanhotos e assim modificamos a nossa primeira leitura. Cabe-nos ressaltar que essa estrutura bipartida, que coloca em diálogo duas histórias (ou versões), ocorre de forma muito semelhante no romance $A$ noite das mulheres cantoras.

Nesse trabalho, interessa-nos a segunda parte do romance $A$ costa dos murmúrios quando temos a voz de Eva Lopo, afastada vinte anos dos acontecimentos do hotel Stella Maris. A mudança do nome Evita/Eva Lopo marca a distância da personagem em relação aos fatos do passado, mas mostra também a sua complexa identidade constituída entre o passado e o presente. Neste momento, Eva Lopo, que outrora era Evita: "Nesse tempo, Evita era eu" (2004, p.49), revive/recupera os acontecimentos do passado desconstruindo o discurso da História oficial.

Eva desarticula o conceito maniqueísta de verdade histórica e aponta para as diferentes possibilidades de se narrar a mesma História, ou melhor, aponta para outras versões dessa História. A identidade da personagem Evita/Eva se constitui através das rememorações desse tempo e, mesmo não adotando mais o nome de Evita, ela não pode e não consegue ignorar os acontecimentos do passado. A narração não pode oferecer a certeza dos fatos, abrindo espaço para a subjetividade das experiências vividas. É o que faz Eva ao recuperar os acontecimentos do casamento e da guerra colonial mostrando a sua visão dos fatos. 
Evidencia-se que o romance pretende dar uma versão da guerra a partir dos sentidos de uma mulher que foi para Moçambique. Eva Lopo pede ao narrador d' Os gafanhotos para não se preocupar "com a verdade que não se reconstitui, nem com a verossimilhança que é uma ilusão dos sentidos. Preocupa-se com a correspondência. Ou acredita noutra verdade que não seja a que se consegue a partir da correspondência?” (2004, p.42-43). Segundo Eva Lopo, as figuras representadas não estão erradas, aliás, "a correspondência é perfeita" (2004, p.43). Nas palavras de Eva, o hotel Stella Maris aparece como um hotel decadente simbolizando a decadência do império português. Não a verdade dos acontecimentos, o que importa é a correspondência como pode ser comprovado pelo fato de o jornalista jamais ter pisado no terraço do hotel, mas pode muito bem ter "ter imaginado o terraço" (2004, p.44). Eva é deslocada para o tempo passado e é como se estivesse revivendo os momentos, principalmente pela utilização do presente do indicativo: "Vejo os últimos pássaros espantados desaparecem, diminuírem pouco a pouco" (2004, p.55). Isso acontece também porque "todas as pessoas, mesmo as mais serenas, mesmo as que se comportam na vida como vinhas, guardam na memória o momento de um terremoto de que contam pormenores como se tivesse acontecido ontem, ao atravessarem a rua" (2004, p.226). Os momentos vividos em Moçambique e no hotel Stella Maris representam "o momento de um terremoto" que sobrevive na e pela memória.

A literatura consegue articular com maestria o tempo cronológico e o tempo psicológico e, segundo o professor Ricardo Timm, ela seria uma "espécie extremamente peculiar de memória materializada", em outras palavras, ela "é a memória do presente" (2013, p.65; grifo do autor). Como já observava Gérard Genette, "uma das funções da narrativa é cambiar um tempo num outro tempo" (1980, p.31) sendo capaz de criar a ilusão de fluxo temporal, ou melhor, a ideia de um "pseudo-tempo" ao articular "as relações entre a ordem temporal e a sucessão dos acontecimentos na diegese" (GENETTE, 1980, p.32). Tal articulação está colocada nos dois romances de Lídia Jorge em que as diferentes temporalidades propõem um novo olhar para o presente, o passado e o futuro.

Tomando de empréstimo as palavras de Walter Benjamin, que as utiliza para descrever a História, nesta perspectiva o tempo da narrativa também é "um tempo saturado de 'agoras" (1986, p.229), claro que sem o compromisso com a "verdade" dos fatos, já que a memória ressignifica o passado no presente. Ela permite reelaborar as identidades e reconstruir o passado a partir das exigências do presente. Eva, ao olhar para o passado, está na tentativa de reorganizar o presente partindo das experiências do passado. Sendo assim, 


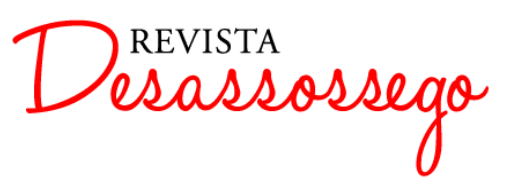

destaca-se a negação da ordem tradicional de apresentação dos eventos narrados, não mais uma natureza cronológica, mas uma natureza mnemônica. A ficcionalidade não corresponde a um tempo cronológico, mas a um tempo da memória. Em Os gafanhotos, a morte dos negros envenenados por álcool metílico aparece em "um desaparecer suave, para quem imagina que a água invade os tecidos como uma esponja a bebe, e depois a escorre, sem alarde nem dor" (JORGE, 2004, p.95). No segundo relato, os corpos na costa não aparecem da mesma forma como fora retratado no primeiro relato. Em Os gafanhotos "seria uma bela morte", mas "na realidade, os que vieram por mar, apareceram inchados e batidos pelas águas até delirem os membros” (JORGE, 2004, p.65).

Eva está tentando elucidar "os pequenos músculos que existem atrás do curso da História" (JORGE, 2004, p.198). Olha os fatos com distanciamento: "Só que nesse momento ainda nenhuma parte dessa teiazinha entrou da teia da História. Mas entrará" (JORGE, 2004, p.202). Evita, quando esteve no hotel Stella Maris, já mostrava ser uma mulher diferente das outras, pois transita fora do hotel, não aceita o pedido do noivo para ficar a sua espera e questiona os crimes cometidos pelo regime. Vinte anos após, agora Eva, aquela que comeu o fruto proibido, é capaz de olhar para os fatos com mais clareza, entretanto desde sempre "Evita pôde. Como sabe, eu fui Evita - um nome que parece frágil se associado à inocência. Evita contudo já tinha pêlo vermelho, sua barbicha de bode “(JORGE, 2004, p.225).

A estrutura bipartida do romance, obedecendo a formas diferentes de narrar, mostra também a relação entre uma memória individual (Eva Lopo) e a memória coletiva representada pelos outros discursos que são transpostos para a narração, evidenciando os vários sentidos incutidos na ideologia portuguesa. As duas partes apontem para versões diferentes dos acontecimentos, mas sem buscar uma versão verídica e sim que corresponda com as possibilidades de leitura da guerra colonial. Sempre uma versão cheia de murmúrios o que comprova que $A$ costa dos murmúrios pode ser lido como um romance que extrapola os limites da relação entre a História e a ficção, constituindo-se um excelente exemplo de narrativa que se insere no conceito de metaficção historiográfica - conforme proposto por Linda Hutcheon. Ou melhor, podemos analisar as duas narrativas a partir dessa visão.

A autora defende que o pós-modernismo, sem ser nostálgico ou saudosista, através da metaficção historiográfica, faz uma subversão da história. Na metaficção historiográfica, a história deixa de ser um processo retilíneo, abre-se espaço para a busca de uma história desmistificada e dessacralizada. No passado, a história já foi diversas vezes utilizada como 
um modelo de representação realista, todavia “ a ficção pós-moderna problematiza esse modelo com o objetivo de questionar tanto a relação entre a história e a realidade quanto a relação entre a realidade e a linguagem" (HUTCHEON, 1991, p.34).

Eva e Solange são personagens complexas e de difícil definição. Percebe-se que elas estão em constante questionamento em relação ao passado e ao seu próprio discurso. $A$ noite das mulheres cantoras, publicado em 2011, tem uma estrutura semelhante ${ }^{2}$ à utilizada em $A$ costa dos murmúrios. O romance também está dividido em duas partes. Inicia com um prólogo, intitulado Noite Perfeita, composto por 18 páginas e que no final recebe o nome "O conto de Solange". Entretanto, no romance $A$ noite das mulheres cantoras, toda a narração está construída sob o ponto de vista da personagem Solange Matos. O romance centra-se no mundo do espetáculo e do imediatismo televiso - "o reino do império minuto", como é designado. Narra-se a história de um grupo musical composto por cinco mulheres jovens (todos imigrantes de diferentes países da África) na década de 80. Um grupo que fez de tudo para alcançar a fama, sendo capaz de ignorar um trágico incidente como foi a morte da integrante Madalena Micaia.

Madalena não só desobedece às regras impostas pela líder Gisela Batista como também engravida e teve o filho no momento mais crítico para o êxito do projeto: a gravação do primeiro disco e a realização do primeiro espetáculo. Para não atrasar o grupo, apressa-se e retoma os ensaios, sem respeitar o descanso pós-natal e acaba por morrer na garagem onde acontecia os ensaios. Sob o comando do padrasto de Gisela, a morte é ocultada e o corpo desaparece.

$\mathrm{Na}$ narração da integrante Solange Matos, os dois momentos se interpõem. $\mathrm{Na}$ primeira parte, Solange narra "a noite do império minuto", noite que as antigas integrantes do grupo se reencontram após vinte e um anos. O ponto de partida é um relato "O conto de Solange" (ou a Noite Perfeita), datado de 16 de novembro de 2009, relato que a escritora teria tido acesso, como anuncia no preâmbulo:

As páginas que me chegaram às mãos e me permitiram escrever este livro eram em número de trinta e quatro, não vinham acompanhadas por título, e alguns nomes e factos eram diferentes. Nesta versão alargada, é ainda da minha inteira responsabilidade todo o resto e sua imperfeição (JORGE, 2012, p.9).

\footnotetext{
2 Inicialmente há um preâmbulo "Nota sobre este livro" e no final "Um epílogo para mais tarde".
} 
$\mathrm{Na}$ primeira parte, Solange, inebriada pela felicidade desse momento, descreve o reencontro: "Mas nós rodopiávamos indiferentes aos brilhos projectados sobre as nossas roupas, porque sabíamos que estávamos a celebrar um encontro no interior do império minuto, e havia vinte e um anos que na realidade não nos encontrávamos" (JORGE, 2012, p.12). A experiência daquela grande noite se prolonga no tempo: "Assim foi, mas quando entramos pelo rés-do-chão adentro, ainda nos encontrávamos no interior da noite minuto. Poucos poderão gabar-se de terem vivido um momento assim. Olhássemos para onde olhássemos, à nossa volta, tudo era perfeição e harmonia" (JORGE, 2012, p.28).

$\mathrm{Na}$ segunda parte, composta por vinte capítulos, três meses após o reencontro do grupo, Solange de Matos também olha para o passado na intenção de contestar aquela noite perfeita em que elas reapareceram em um espetáculo televisivo. Retoma o momento no cineteatro quando João Lucena veio ao seu encontro. Após três meses daquele reencontro, já não era mais possível ignorar os fatos, era preciso encarar "a noite imperfeita dos séculos" (JORGE, 2012, p.26). O passado foi desorganizado e a memória seria como uma porta de acesso ao interior da personagem.

Ricoeur, em Tempo e narrativa, logo no início do primeiro tomo, retoma o estudo de Santo Agostinho do livro XI das Confissões. Diz-nos o autor, "estamos (...) prontos a considerar como seres não o passado e o futuro como tais, mas qualidades temporais que podem existir no presente " (1994, v.1, p.26). O autor compreende a narrativa como uma forma de constituição do sujeito a partir da relação entre a narratividade e a temporalidade. Mas, como a narrativa rearticula o passado, presente e o futuro? " Como o tempo pode ser, se o passado não é mais, se o futuro não é ainda e se o presente nem sempre é?” (1994, v.1, p.22).

Para responder tal aporia, o filósofo parte das observações de Agostinho ao considerar que o passado e futuro estão colocados no presente através da memória e da espera. Dessa forma, a memória é o "presente do passado" (RICOEUR, 2007, p.364). É através da narração que rememoramos o passado e antecipamos o futuro. Todavia, observando "que o que se mede não são as coisas futuras ou passadas, mas a sua espera e sua recordação " (RICOEUR, 1994, v.1, p.40). A imagem do passado e a perspectiva do futuro, "quaisquer que elas sejam, não podem existir senão no presente" (AGOSTINHO, 1987, p.282).

$\mathrm{Na}$ segunda parte, Solange regressa ao tempo em que era uma estudante universitária. Não há mais possibilidade de o passado permanecer intocado, "com todos os 


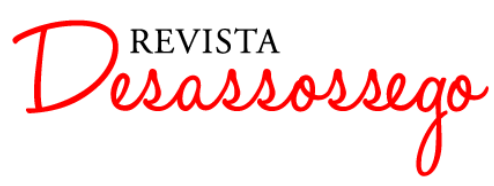

seus fatos tão fechados, tão definidos “(JORGE, 2012, p.29). Distante dos fatos, Solange tenta recuperar a sua imagem de moça ingênua aos dezenove anos. Suas lembranças vão além do que aconteceu naquela Noite Perfeita (relembra a sua infância, quando seus pais foram expulsos da África, quando entrou no grupo, os ensaios, a relação do grupo com a líder Gisela Batista, o namoro com João Lucena, etc.). Vinte e um anos atrás, Solange era uma estudante da Universidade de Lisboa. Recatada e obediente: “ Na minha ideia, toda paisagem humana era uma extensão da família, e o narrador da minha vida era o meu pai “ (JORGE, 2012, p.29). Submissa ao pai, à Gisela e ao namorado João Lucena: "Eu amava o que ela amava e detestava o que ela detestava" (JORGE, 2012, p.137); “ tudo o que ele me indicar para fazer eu farei" (JORGE, 2012, p.258).

A noite do reencontro desperta uma história que parecia estar adormecida: "E se saltássemos para cima do palco, e se disséssemos a verdade? Se contássemos como tudo se passou" (JORGE, 2012, p.23). Buscando respostas dentro das suas memórias vividas, a partir das próprias experiências, recria-se na narração. Contudo, a compreensão de si é um exercício hermenêutico que coloca em jogo vários questionamentos. Assim como Eva, a percepção de Solange vai além do maniqueísmo verdade versus mentira:

Gisela não mentia, o passado que era imperfeito, e para os seus factos se adaptarem ao entendimento do presente, o relato que dele se fizesse carecia de ser transformado. Apenas isso. Nem sequer se poderia falar de fantasia. Não, não era fantasia. Tratava-se tão só de uma outra verdade (JORGE, 2012, p.24).

Mesmo com o passar do tempo, há episódios que permanecem mais nítidos na memória: "Lembro-me como se fosse hoje" (JORGE, 2012, p.40). Outros acontecimentos ganham uma nova percepção sob o olhar do presente: "Nesse momento, estou diante da janela aberta sobre a Praça das Flores (...) e eu regresso ao fundo do nosso tempo, aquilo que parecia ter sido apenas um pequeno acidente sem consequência” (JORGE, 2012, p.48). Acontecimentos que só agora são entendidos: "Como é que nunca tinha compreendido" (JORGE, 2012, p.104). É preciso reinterpreta-los, porque só deste modo conseguirá seguir em frente: "No fundo, éramos um bando de cinco mulheres amadoras, tentando ocupar um espaço que não nos competia” (JORGE, 2012, p.130). Como Eva Lopo, Solange sabe que nem tudo pode ser explicado: "Mas nem tudo o que é inesquecível deve ser descrito. A maior parte da nossa experiência inesquecível pode permanecer para sempre indizível. Assim, quando imagino esses dias do mês de janeiro, penso na invisibilidade das coisas" 


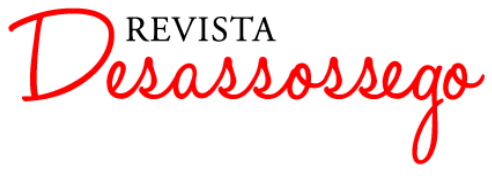

(JORGE, 2012, p.119). Como acontece com a morte da colega Madalena Micaia: “ Mas a partir dali, é preciso omitir o que se segue" (JORGE, 2012, p.226).

É necessário escolher o que quer lembrar e escolher o que quer esquecer: " é preciso esquecer a grande carrinha a embalar rua afora, esquecer a Gisela diante do frigorífico" (JORGE, 2012, p.227). Não é possível falarmos em memória sem consideramos a sua relação com o esquecimento. Sempre há algo que ficou perdido nas malhas do tempo e a narração só conseguirá recuperar parte de um testemunho. Mais do que apontar respostas, a narração deixa latente um certo problema: a impossibilidade da memória dar conta de todos os eventos precedentes. Diferente de Eva, Solange, mesmo com o passar dos anos, em alguns aspectos ainda permanece ingênua. Ela é incapaz de perceber que João Lucena tem relações com outros homens. Na parte final intitulada "Epílogo para mais tarde" percebe-se que Solange continua apaixonada por Lucena, vivendo na memória desse amor que começou há duas décadas:

\footnotetext{
Mesmo embrulhado no casaco de astracã, uma vez ao ar livre, o ocupante tem frio. Ele aí está. A cancela já se abriu, ele já reentrou, a porta de ligação ficou fechada, neste momento já ele afastou a coberta da otomana, já retirou os sapatos, e agora já se deitou. Acaso terá ligado o candeeiro da mesa? (JORGE, 2012, p.295).
}

Ainda vivendo na sombra no seu antigo amor (já que João Lucena mora no rés-dechão da sua casa): "Pois é domingo, e agora já anoiteceu de todo. Ouço os copos a serem pousados sobre o tabuleiro, os pratos a serem desempilhados. Alguém partiu um objecto de vidro. Alguém varre os pedaços” (JORGE, 2012, p.317).

É importante observar que em ambos os romances, o passado recupera uma experiência coletiva (a guerra colonial/o grupo de música), ou seja, há uma relação entre uma memória individual e coletiva. Em Memória e identidade, Joël Candau parte do pressuposto de que a memória e a identidade "estão indissoluvelmente ligadas" (2011, p.10); a identidade é construída através "de uma construção social, de certa maneira sempre acontecendo no quadro de uma relação dialógica com o Outro" (2011, p.9). Um dos objetivos do livro de Joël Candau é mostrar como "passamos de formas individuais a formas coletivas da memória e identidade" (2011, p.11). Segundo o autor, a memória "nos modela", mas "é também por nós modelada" (2011, p.16). O estudioso traz as palavras de Anne Muxel ao articular que "o trabalho da memória atua na construção da identidade do 
sujeito; é o "trabalho de reapropriação e negociação que cada um deve fazer em relação ao seu passado para chegar a sua própria individualidade" (2011, p.16).

Para Joël Candau, a constituição da memória exige determinadas estratégias em que “os indivíduos operam escolhas sempre no interior de um repertório flexível e aberto a diferentes meios: representações, 'mito-histórias', crenças, ritos, saberes, heranças, etc., ou seja, no interior de um registro memorial” (CANDAU, 2011, pp.17-18). Os eventos do passado rememorados passam por um filtro e então "a lembrança não é a imagem fiel da coisa lembrada, mas outra coisa, plena de toda a complexidade do sujeito e da sua trajetória de vida" (CANDAU, 2011, p.65). Dessa forma, as identidades "são produzidas e se modificam no quadro das relações, reações e interações sociossituacionais - situações, contexto, circunstâncias -, de onde emergem os sentimentos de pertencimento, de 'visões de mundo' identitárias ou étnicas" (CANDAU, 2011, p.27).

É quase impossível separar a memória individual da coletiva. "Muitas das nossas lembranças existem porque encontramos eco a elas" (CANDAU, 2011, p.77), entretanto, um grupo pode compartilhar as mesmas vivências, mas isso não significa que as lembranças evocadas serão as mesmas, já que dependerá da forma como cada um irá acessar essas informações (CANDAU, 2011). Assim sendo, a reminiscência é o resultado das escolhas a partir das semelhanças e das diferenças - "que o indivíduo vai construir e impor sua própria identidade" (CANDAU, 2011, p.84).

Em $A$ costa dos murmúrios e em $A$ noite das mulheres cantoras, a recuperação do passado passa pelo crivo da memória, das subjetividades de quem tenta recuperá-lo, do contexto e do momento em que ele está sendo reavaliado. A intenção não é validar os acontecimentos do passado, mas abrir mais possibilidades de significação. Se o passado realmente existiu, “[...] esse passado foi real, mas está perdido ou, ao menos, deslocado, apenas para ser restabelecido como referente da linguagem ou vestígio do real” (HUTCHEON, 1991, p.188). Isso não quer dizer que a pós-modernidade nega o referente, mas ela quer problematizar a referência, preponderantemente, ao defender que estamos lidando com "fatos" em vez de "acontecimentos". "A metaficção historiográfica não pretende reproduzir acontecimentos, mas, em vez disso, orientar-nos para os fatos, ou para as novas direções a tomar, para que pensemos sobre os acontecimentos" (HUTCHEON, 1991, p.198). De acordo com o novo historicismo, "o sentido e a forma não estão nos acontecimentos, mas nos sistemas que transformam esses 'acontecimentos' passados em ‘fatos' históricos presentes” (HUTCHEON , 1991, p.122). 
O que Lídia Jorge, ao lado de outros autores da literatura portuguesa contemporânea, nos mostra é que as identidades são construídas em práticas discursivas específicas. E o lugar de onde se fala é extremamente significativo para entendermos qual é o discurso. Para tentar entender o imaginário português, Eduardo Lourenço busca aporte na ficção, pois, já que não podemos descortinar a verdade de uma cultura, ela melhor representa a nação lusófona ao articular o imaginário, o ficcional e o histórico. Lourenço não exclui a possibilidade de existência de um imaginário lusófono, mas ele não pode ser criado por decisão política e sim a partir do imaginário coletivo. Por isso as narrativas sobre esse tempo são importantes, pois como nos disse Eva Lopo

Se ninguém mais voltar a mostrar-me uma narrativa sobre esse tempo, se nunca mais evocar esta lembrança à luz duma lâmpada ocasional como a sua, o Stella inteiro iluminado à beira do Índico, que foi de vidro, areia e cal, acabará aqui. O seu pequeno fulgor, que eu penso existir ainda dentro da cabeça de cem, duzentas pessoas vivas (...) acabará à medida que as pessoas se forem deitando nas marquesas e os médicos forem dizendo, com seus terríveis assentos de morte, condenado. E assim o Stella (...) será enterrado pouco a pouco, aos pedaços, à medida que a geração que o viu suspire e acabe (JORGE, 2004, p. 230-231).

Sem dúvida, Lídia Jorge nos permite uma reflexão sobre a produção feminina em Portugal. Sabe-se que, em virtude da ditadura (1926-1974), a emancipação social da mulher portuguesa é tardia. Por exemplo, o direito ao voto só foi ocorrer depois do 25 de Abril de 1974. Sabemos que nas últimas décadas as mulheres alcançaram uma projeção social e econômica, entretanto após tanto tempo de silêncio, a literatura feminina tem a tarefa de (re)formular uma identidade assim como pensar no seu lugar no cânone. É isso que Lídia Jorge faz através de narrativa de densa experimentação em que a figura da mulher tem um papel importantíssimo - como pode ser observado já no seu primeiro romance $O$ dia dos prodígios (1980), que já discutia os valores de uma sociedade patriarcal.

\section{Referências bibliográficas}

AGOSTINHO, Santo. Confissões. Petrópolis, Editora Vozes, 1987.

BENJAMIN, Walter. "Sobre o conceito da História". In: BENJAMIN, Walter. Magia e técnica, arte e politica: ensaios sobre literatura e história da cultura. $2^{\mathrm{a}}$.ed. Trad. Sergio Paulo Rouanet. São Paulo: Brasiliense, 1986. pp.222-32. (Obras escolhidas; v. 1). 
CANDAU, Joël. Memória e identidade. Tradução Maria Leticia Ferreira. - São Paulo: Contexto, 2011.

GENETTE, G. Discurso da Narrativa. Tradução Fernando Cabral Martins. Lisboa, Vega, 1980.

HUTCHEON, Linda. A poética do pós-modernismo: história, teoria, ficção. Tradução Ricardo Cruz. Rio de Janeiro: Imago, 1991.

JORGE, Lídia. A costa dos murmúrios. Rio de Janeiro: Record, 2004. A noite das mulheres cantoras. São Paulo: Leya, 2012.

LOURENÇO, Eduardo. Nós e a Europa on as duas razooes. Lisboa: Imprensa Nacional Casa da Moeda, 1988.

RICOEUR, Paul. Tempo e narrativa. Trad. Constança Marcondes César. v.1 Campinas: Papirus, 1994. - A memória, a história, o esquecimento. Trad. Alain François [et al.]. Campinas: Editora Unicamp, 2007.

SOUZA, Ricardo Timm de. "Escrever o livro do mundo: Memória como substância ética da literatura, ou: a obra literária como memória do presente”. In: MELLO, Ana Maria Lisboa de (org.). Escritas do eu: introspeção, memória e ficção. Rio de Janeiro: 7Letras, 2013.

Data de recebimento: 02/05/2017

Data de aprovação: 18/12/2017 